\title{
The Absence of Superficial Palmar Arch with Persistence Median Artery: A Case Report
}

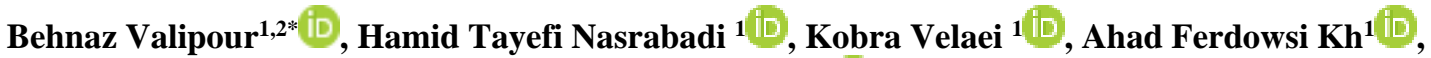 \\ Khadijeh Dizaji Asl ${ }^{1}[\mathbb{D}$
}

1. Dept. of Anatomical Sciences, Faculty of Medicine, Tabriz University of Medical Sciences, Tabriz, Iran

2. Dept. of Histopathology, Tabriz Branch, Islamic Azad University, Tabriz, Iran

\begin{tabular}{|c|c|}
\hline Article Info & ABSTRACT \\
\hline doi $10.30699 /$ jambs.27.125.57 & \multirow{3}{*}{$\begin{array}{l}\text { The prominence of the hand function is underlined fundamentally by its rich vascular } \\
\text { system. The superficial palmar arch incredibly provides hand with the blood supply, } \\
\text { which is normally formed by the ulnar artery and superficial palmar branch of the } \\
\text { radial artery. In the current case, the unilateral absence of superficial palmar arch with } \\
\text { the rare presence of the median artery was reported, which was noticed in the right } \\
\text { hand of a male cadaver during a routine educational dissection. The awareness of } \\
\text { particular variations in hand blood supply during hand operations leads in preventing } \\
\text { surgical mistakes. }\end{array}$} \\
\hline $\begin{array}{c}\text { Received: 2019/07/13; } \\
\text { Accepted: 2019/08/25; } \\
\text { Published Online: } 27 \text { Aug 2019; }\end{array}$ & \\
\hline $\begin{array}{r}\text { Use your devi } \\
\text { art }\end{array}$ & \\
\hline
\end{tabular}

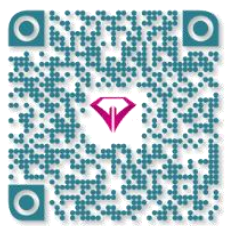

Keywords: Hand, Persistence Median Artery (PMA), Superficial Palmar Arch (SPA)

Corresponding Information:

Behnaz Valipour: Dept. of Anatomical Sciences, Faculty of Medicine, Tabriz University of Medical Sciences, Tabriz, Iran and Dept. of Histopathology, Tabriz Branch, Islamic Azad University, Tabriz, Iran. E-mail: behnaz.valipour1@gmail.com

(1) (5) Copyright $\odot$ 2019, This is an original open-access article distributed under the terms of the Cred

\section{Introduction}

In the upper extremity, the brachial artery arising from the axillary artery passes through intermuscular septum as the powerful blood source toward the cubital fossa. In the cubital fossa at the level of the neck of radius, it subdivides into the radial and ulnar arteries. The following duplicate system serves as an important source of arterial supply (1). In due course, the hand is supplied by the terminal branches of the ulnar and radial arteries through the superficial and deep palmar arch (SPA and DPA). The SPA is a specific arterial arch that is located between the palmar aponeurosis and the long flexor tendons. Typically, the SPA is composed of a terminal branch of the ulnar artery and the superficial (palmar) branch of the radial artery. Ulnar artery enters the palm anteriorly to the flexor retinaculum then passes medial to the hook of the hamate and curves laterally for the anastomosis with the superficial (palmar) branch of the radial artery $(2,3)$. Three common palmar digital arteries (CPDA) give rise to the SPA and finally supply blood for the contiguous sides of 2, 3, 4, and 5th fingers. The radial side of the index finger and the thumb are supplied by the branches of the radial artery. Additionally, the thenar and hypothenar regions, lumbrical muscles, and skin of palm gain some branches from the SPA (4). The vascular pattern of the palmar arches is complicated.
Numerous classifications are reported based on various studies. SPA is characterized into two categories: complete (with anastomosis in arteries) and incomplete arch (without anastomosis in arteries) (5). Therefore, the median artery associated with the median nerve (MN) appears as a temporary artery during the embryonic period to provide blood supply to the hand. After appearing ulnar and radial arteries in the 8th week of gestation, the median artery retrogrades to the small vessel accompanying the median nerve or disappears completely (6). Persistence of the median artery in adult life occurs in $4 \%$ of cases and may compress the $\mathrm{MN}$ in hand. The complexity of the vascular pattern in hand has gained more attention among researchers. A high frequency of SPA variations is of great clinical importance for surgical approaches. Knowledge about variations of arteries in hand helps the surgeon to carry out a comprehensive assessment during surgery. In the current case, a unilateral Mediano-ulnar type of incomplete SPA is reported for emphasizing awareness of such variation in academic and clinical intentions.

\section{Case Report}


During routine dissection of the upper extremity for undergraduate students in the department of anatomy in the Medical Faculty of Tabriz University, a unilateral variation of SPA was noticed in the right hand of an Iranian male cadaver, which was embalmed in formalin solution for 6 months in order to fixate. The dissection of the upper extremity was performed to exhibit the whole muscles, arteries, and vessels based on Cunningham's manual of practical anatomy instructions (7). On the right side of the forearm area, three major artery branches were observed in the lower part of the cubital fossa (Figure 1). Between radial and ulnar arteries, the third major branch that is associated with the median nerve was considered as a median artery, which persists in only $4 \%$ cases of adults.
However, the interosseous artery did not develop and accompanied by an interosseous nerve branch. Therefore, the median artery originated directly from the ulnar artery. The dissection process continued toward the hand to clear the terminal branches of these arteries. Surprisingly, the SPA was missed in the palm area, and the radial artery did not appear in the SPA. Median artery instead of radial artery irrigated the first and second interosseous spaces by 2 common palmar digital arteries. Then, the third and fourth common palmar digital arteries separately came from an ulnar artery, the medial side (Figure 2). More investigation was subsequently performed for exposing DPA. However, DPA did not involve any variations (ㅍigure 3).

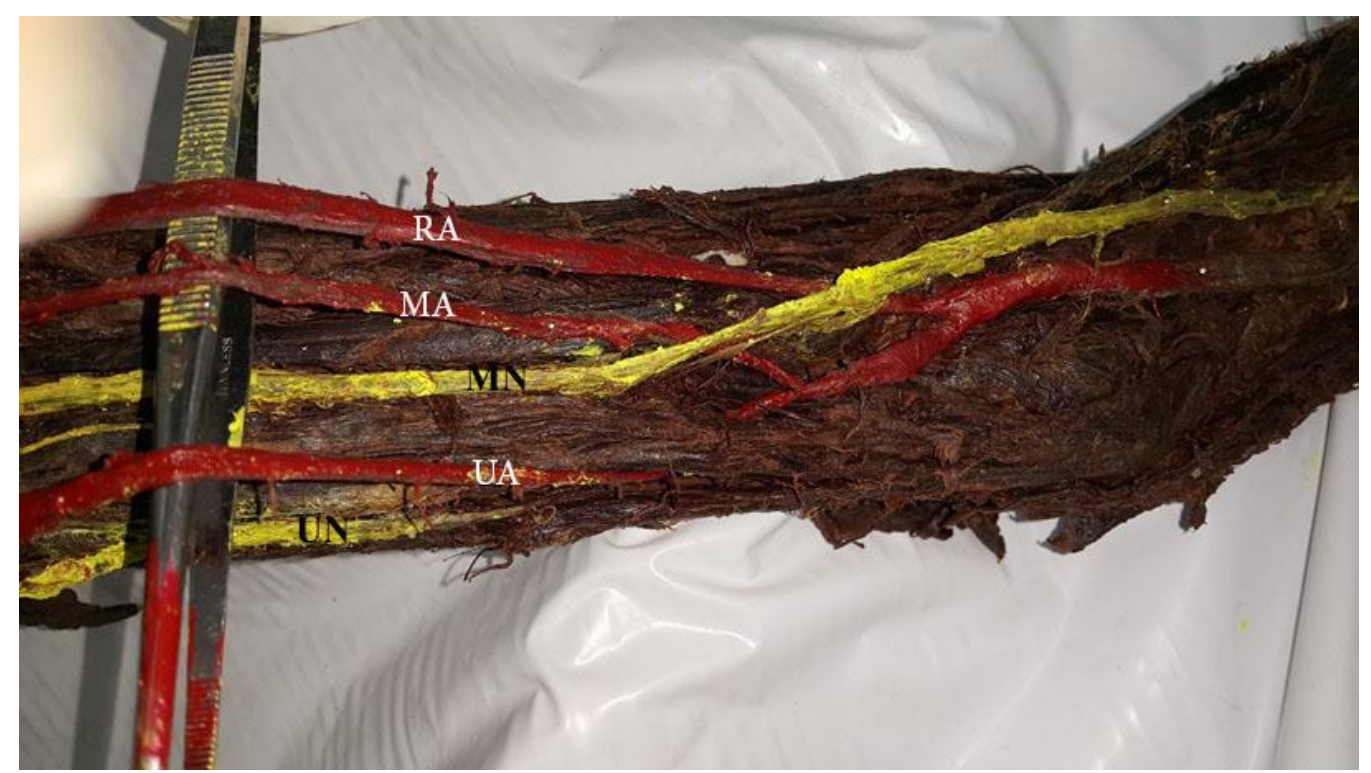

Figure 1. Arteries in the lower part of the cubital fossa

RA: Radial Artery, MA: Median Artery, UA: Ulnar Artery, MN: Median Nerve, UN: Ulnar Nerve

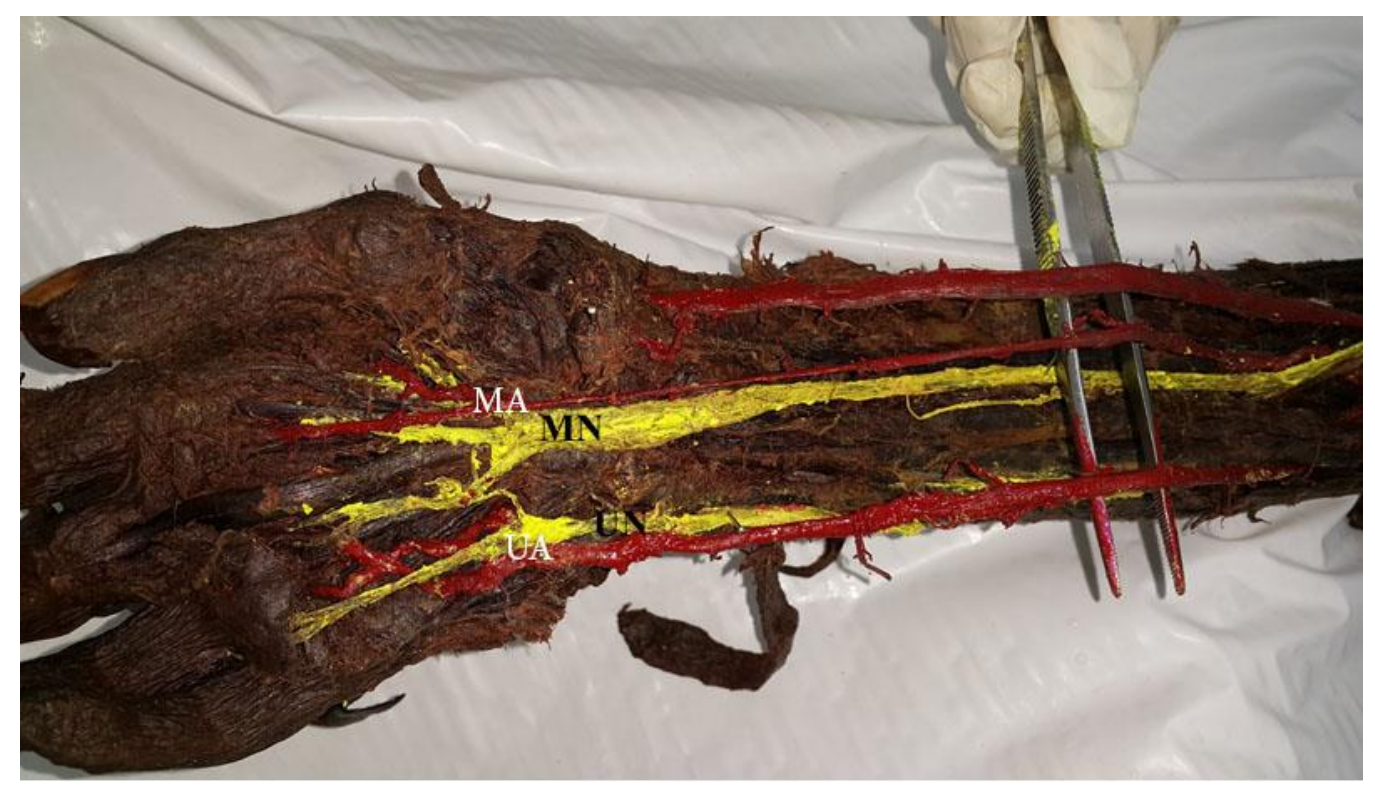

Figure 2. In the absence of SPA situation, MA instead of RA irrigated the first and second interosseous spaces; however, the third and fourth common palmar digitals separately came from UA 


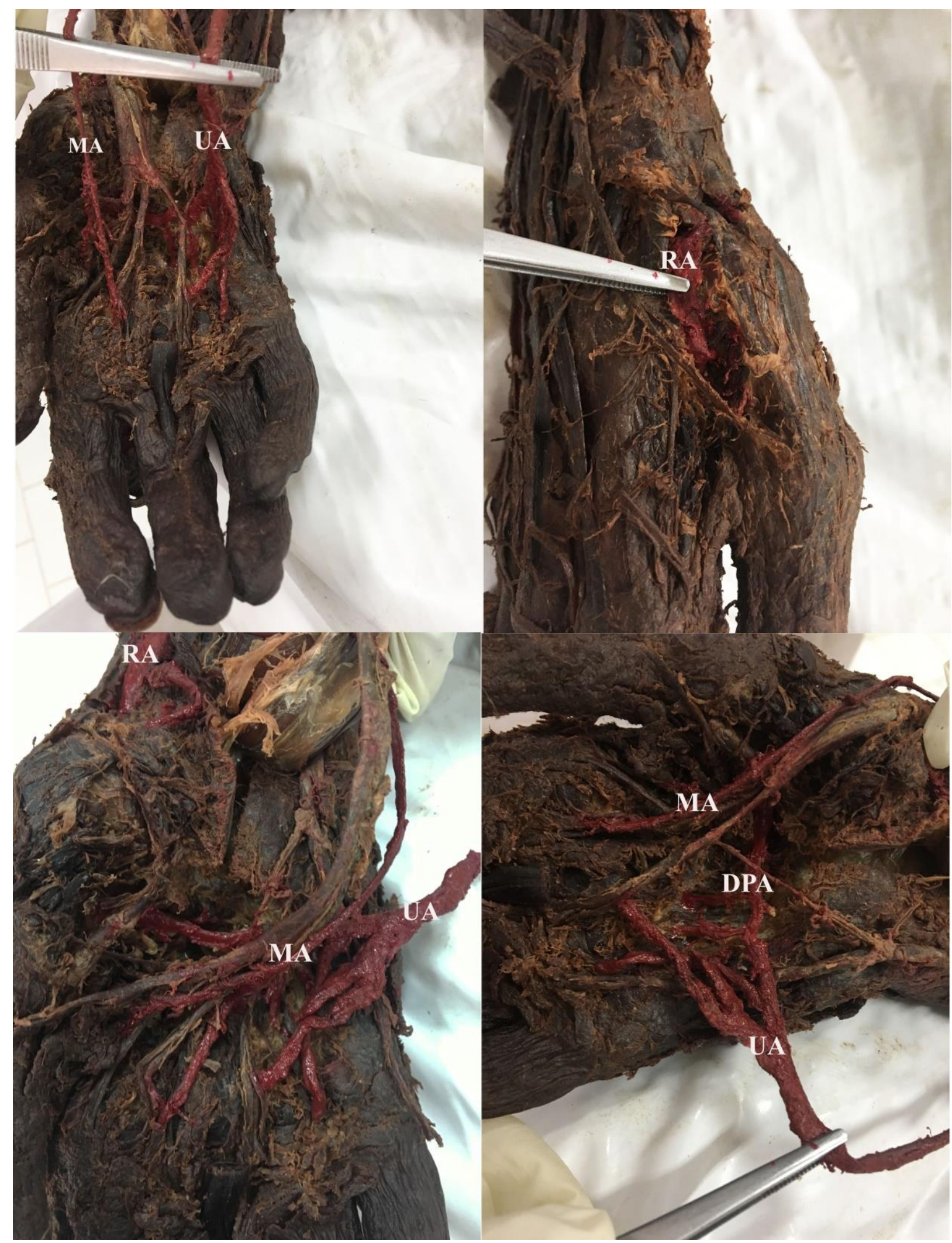

Figure 3. The absence of SPA with normal DPA 
DPA: Deep Palmar Arch, RA: Radial Artery, MA: Median Artery, UA: Ulnar Artery

Table 1. The classification of superficial palmar arches according to Coleman and Anson (from references 9)

\begin{tabular}{|c|c|c|c|c|c|}
\hline Group & $\mathbf{A}$ & B & C & D & $\mathbf{E}$ \\
\hline Complete Arch (I) & $\begin{array}{c}\text { Superficial palmar } \\
\text { branch of radial artery } \\
\text { + larger ulnar artery } \\
(4 \%)\end{array}$ & $\begin{array}{c}\text { Entirely by the } \\
\text { ulnar artery } \\
(56 \%)\end{array}$ & $\begin{array}{l}\text { Ulnar artery } \\
\text { + enlarged } \\
\text { median artery }\end{array}$ & $\begin{array}{l}\text { Radio- } \\
\text { Mediano-ulnar } \\
\text { arch }\end{array}$ & $\begin{array}{l}\text { Ulnar artery + large- } \\
\text { sized vessel derived } \\
\text { from deep arch }(22 \%)\end{array}$ \\
\hline Incomplete Arch (II) & $\begin{array}{c}\text { Superficial palmar } \\
\text { branch of the radial } \\
\text { artery }+ \text { ulnar artery } \\
(4 \%)\end{array}$ & $\begin{array}{l}\text { Ulnar artery } \\
\text { only } \\
(10 \%)\end{array}$ & $\begin{array}{c}\text { Superficial } \\
\text { vessels of } \\
\text { median } \\
+ \text { ulnar arteries } \\
(4 \%)\end{array}$ & $\begin{array}{c}\text { Superficial } \\
\text { vessels of } \\
\text { Radial } \\
+ \text { median + } \\
\text { ulnar arteries }\end{array}$ & \\
\hline
\end{tabular}

\section{Discussion}

Human hand anatomy is the primary focus of surgeries and radiologist due to its complexity in vascularization and crucial role in microvascular surgery. Arterial supply for hand is derived from two superficial and deep palmar anastomotic arches. SPA is the principal vascular structure of the palm. Many attempts have been made to find the appropriate classification of vascular pattern in the hand region (8). The most famous one is the classification of Coleman and Anson based on which the superficial palmar arch has been classified into two groups, Group I and Group II, and each group_has been divided into several subtypes (Table 1) (9). The predominant type is Group I (Type A), a superficial palmar branch of radial artery anastomosis with ulnar artery to form the arch. In the present study, the incomplete superficial arch has been discovered. This current variation in SPA fits into the Type C (Group II) category, according to Coleman and Anson classification (10). In a study conducted by Ikeda A et al. (1988), the complete arch was recorded in $96.4 \%$ of the cases and incomplete arch in the remaining $3.6 \%$ (11). However, a complete arch was reported in $84.4 \%$ of the cases in another study (12). Bataineh et al., in 2009, reported a rare variation in which superficial palmar arch was found in an incomplete type that has been formed by the median and ulnar artery. The princeps policies and radialis indicis arteries have been originated from a median artery. In addition, the ulnar artery supplied the most interosseous spaces except for the second space (13). In the present case report, an incomplete arch was found in which the ulnar artery directly supplied the third and fourth interosseous spaces. Also, the persistent median artery (PMA) was terminated uniquely as the common palmar digital for the first and second interosseous spaces. Accidental injury during surgical procedures or occluding artery on one side of the wrist could be compensated by collateral circulation. Hence, incomplete superficial palmar is important concerning the clinical aspect (5). Inefficient blood supply may induce digital ischemia and disturb movements of fingers and hands. Variations in the SPA may be due to initial persistence network of fetus vessels like the median artery, which normally undergoes regression in the embryonic period. PMA can originate from different sources, such as brachial, ulnar, radial, or interosseous arteries (14). In the present study, PMA raised from the ulnar artery. Clinically, MN may be compressed by the pressure of PMA; consequently, compressive neuropathies like Carpal Tunnel Syndrome (CTS) may happen (6). Embryological anatomical studies have suggested that the presence of the PMA may be explained with some theories. One distinct possibility is the retention of primitive patterns as a branch of the embryological axial artery. Another hypothesis explains that, in a proximal-to-distal differentiation pattern, the upper limb arteries develop from an initial capillary plexus. Variations in the formation of SPA or PMA may be a result of the differentiation, maintenance, and enlargement of certain capillary vessels while others undergo regression (6). Although the exact mechanism of this variation has not been identified, some factors, such as chemical factors, developmental arrest in early stages, fetal position in the uterus, and genetic factors, have been suggested to be involved in this variation $(15,16)$. Knowledge of SPA variations or PMA is vitally important because of the contribution to many surgical and diagnostic problems.

\section{Conclusion}

It is noteworthy to consider this variation before any surgical practice or other interference in the hand region. Also, these relationships may have contributed to the diagnosis and treatment of various tunnel syndromes related to the $\mathrm{MN}$ or its branches.

\section{Acknowledgment}

The authors wish to thank all those who donate their bodies to advance the education and research.

\section{Conflict of Interest}


Authors declared no conflict of interests.

\section{References}

1. Higgins JP, McClinton MA. Vascular insufficiency of the upper extremity. J Hand Surg. 2010;35(9):1545-53.

[DOI:10.1016/j.jhsa.2010.06.011] [PMID]

2. Agur AM, Dalley A. Grant's Atlas of Anatomy. 13th. Philadelphia: Wolters Kluwer Health/Lippincott Williams \& Wilkins, ISBN; 1999.

3. Standring S. Gray's anatomy e-book: the anatomical basis of clinical practice: Elsevier Health Sciences; 2015.

4. Bilge O, Pinar Y, Özer M, Gövsa F. A morphometric study on the superficial palmar arch of the hand. Surg Radiol Anat. 2006;28(4):343-50. [DOI:10.1007/s00276-006-0109-9] [PMID]

5. Arquez HF, Hurtado DKA. Variations of the superficial palmar arches: A cadaveric study. J Chem Pharmaceut Res. 2016;8(5):6-14.

6. Eid N, Ito Y, Shibata M, Otsuki Y. Persistent median artery: cadaveric study and review of the literature. Clin Anat. 2011;24(5):627-33. [DOI:10.1002/ca.21127] [PMID]

7. Romanes GJ, Cunningham DJ. Cunningham's Manual of Practical Anatomy: Zahlr. Ill. U. Graph. Darst: Oxford University Press; 1986.

8. Huber GC. Piersol's human anatomy. The vascular system. 767-91.

9. Coleman SS. Arterial patterns in the hand based upon a study of 650 specimens. Surg Gynecol Obstet. 1961;113:409-24.
10. Joshi SB, Vatsalaswamy $\mathrm{P}$, Bahetee B. Variation in formation of superficial palmar arches with clinical implications. J Clin Diag Res. 2014;8(4):AC06.

[DOI:10.7860/JCDR/2014/7078.4252] [PMID] [PMCID]

11. Ikeda A, Ugawa A, Kazihara Y, Hamada N. Arterial patterns in the hand based on a threedimensional analysis of 220 cadaver hands. J Hand Surg. 1988;13(4):501-9. [DOI:10.1016/S03635023(88)80085-6]

12. Gellman H, Botte MJ, Shankwiler J, Gelberman RH. Arterial patterns of the deep and superficial palmar arches. Clin Orthop Relat Res (1976-2007). 2001;383:41-6.

\section{[DOI:10.1097/00003086-200102000-00007]} [PMID]

13. Bataineh ZM, Habbal O, Moqattash ST. Variations in the superficial palmar arch of the hand. Italian J Anat Embryol. 2009;114(1):11-20.

14. Nayak SR, Krishnamurthy A, Kumar SM, et al. Palmar type of median artery as a source of superficial palmar arch: a cadaveric study with its clinical significance. Hand. 2010;5(1):31-6. [DOI:10.1007/s11552-009-9197-4] [PMID] [PMCID]

15. Natsis K, Papadopoulou A, Paraskevas G, Totlis T, Tsikaras P. High origin of a superficial ulnar artery arising from the axillary artery: anatomy, embryology, cinical significance and a review of the literature. Folia morphologica. 2006;65(4):400-5.

16. Poteat WL. Report of a rare human variation: absence of the radial artery. Anat Record. 1986;214(1):89-95.

[DOI:10.1002/ar.1092140115] [PMID]

\section{How to Cite This Article:}

Valipour B, Tayefi Nasrabadi H, Velaei K, Ferdowsi Kh A, Dizaji Asl K. The Absence of Superficial Palmar Arch with Persistence Median Artery: A Case Report. J Adv Med Biomed Res. 2019; 27 (125) :57-61

Download citation:

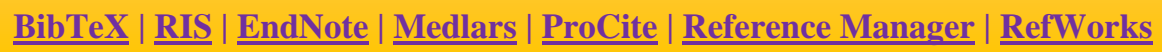

Send citation to:

(3) Mendeley 2 Zotero [-2RefWorks RefWorks 